\title{
PENGARUH LINGKUNGAN KERJA DAN DISIPLIN KERJA TERHADAP KINERJA KARYAWAN DI KOPERASI KSPPS BMT AL-FATH IKMI KEDAUNG PAMULANG
}

\author{
1Ira Marselia, ${ }^{2 *}$ Elizabeth Tika Kristina Hartuti \\ Universitas Pamulang, Tangerang Selatan, Banten, Indonesia \\ *dosen01503@unpam.ac.id
}

\begin{abstract}
Abstrak
Penelitian ini bertujuan untuk menguji pengaruh lingkungan kerja dan disiplinkerja terhadap kinerja karyawan di Koperasi KSPPS BMT AL-FATH IKMIKedaung Pamulang. Jenis penelitian ini adalah kuantitatif menggunakan teknik pengolahan dan analisisdata menggunakan analisis deskriptif, pengujian instrumen data, uji asumsi klasik,uji korelasi dan determinasi, uji hipotesis. Lingkungan kerja dan disiplin kerja berpengaruh positif dan signifikan terhadap kinerja karyawan dengan persamaan regresi $Y=14,570+0,302 X_{1}+0,533 X_{2}$. Hasil ini menunjukkan bahwa koefisien korelasi sebesar 0,664. Dengan nilai $f_{\text {hitung }} \mathrm{f}_{\mathrm{tabel}}$ yaitu $23,639>3,15$ dengan tingkat signifikan $0,000<0,05$. Sedangkan lingkungan kerja terhadap kinerja karyawan dengan nilai thitung $>t_{\text {tabel }}$ yaitu 2,375 $>2,000$ dengan nilai signifikan sebesar 0,001 $<0,005$. Kemudian disiplin kerja dengan nilai thitung $>t_{\text {tabel }}$ yaitu 3,300 $>2,000$ dengan nilai signifikan sebesar 0,002<0,005.

Kata Kunci: Lingkungan Kerja, Disiplin Kerja, Kinerja Karyawan

\section{Abstract}

This research aims to test the influence of the work environment and work discipline on employee performance at the KSPPS BMT AL-FATH IKMI Kedaung Pamulang Cooperative. This type of research is quantitative using data processing and analysis techniques using descriptive analysis, data instrument testing, classical assumption test, correlation and determination test, hypothesis test. The work environment and work discipline positively and significantly affect employee performance with regression equation $Y=14,570+0.302 X 1$ $+0.533 X 2$. These results show that the correlation coefficient is 0.664 . With a fhi $>$ ftable value of $23,639>3.15$ with a significant level of $0.000<0.05$. While the work environment to the performance of employees with a thitung value of $>$ is 2,375>2,000 with a significant value of $0.001<0.005$. Then the discipline of work with a thitung value of $>$ is 3,300 > 2,000 with a significant value of 0.002<00,005.
\end{abstract}

Keywords: Work Environment, Work Discipline, Employee Performance

\section{PENDAHULUAN}

Manajemen merupakan seni untuk melaksanakan dan mengatur. Manajemen menurut Stephen P. Robbins dan Marry Coulter yang dialih bahasakanoleh Ratna Saraswati (2016:36) "Proses mengkoordinasi dan mengintegrasikan kegiatan-kegiatan kerja agar diselesaikan secara efisien dan efektif dengan melalui orang lain". Perusahaan yang dapat bertahan terhadap persaingan tersebut agar dapat berkembang dan tumbuh menjadi perusahaan yang berskala besar. Tumbuhnya skala perusahaan akan mengakibatkan meluasnya kegiatan- kegiatan di perusahaan tersebut sehingga memerlukan banyak perubahan dalam bidang manajemen. Lingkungan kerja merupakan tempat dimana para karyawan melakukan aktivitas bekerja. Lingkungan kerja dalam suatu perusahaan termasuk salah satu hal yang sangat penting untuk diperhatikan. Lingkungan kerja yang memusatkan bagi karyawannya dapat meningkatkan hasil kerja. Sebaliknya lingkungan kerja yang tidak memadai akan dapat menurunkan kinerja dan akhirnya menurunkan hasil kerja karyawan. Lingkungan kerja dapat menciptakan hubungan kerja yang saling mengikat 
dengan orang- orang yang ada di dalam lingkungannya. Disiplin kerja merupakan disiplin waktu kerja, dan disiplin dalam mematuhi peraturan yangtelah ditetapkan dalam perusahaan. Menurut Edy Sutrisno (2016:89) disiplin adalah "Perilaku seseorang yang sesuai dengan peraturan, prosedur kerja yang ada atau disiplin adalah sikap, tingkah laku, dan perbuatan yang sesuai dengan peraturan dari organisasi baik tertulis maupun tidak tertulis".

Dimana dalam perusahaan di Koperasi KSPPS BMT AL- FATH IKMI mengalami penurunan pada tingkat absensinya. Disiplin kerja yang kurang baik akan berakibat buruk dalam menjalankan tugas-tugas, dan hal tersebut dimulai dari disiplin kehadiran. Sebagai data absen disiplin kerja karyawan dapat dilihat pada tabel 1 sebagai berikut:

Tabel 1. Data Absensi Karyawan Tahun 2017 - 2018

\begin{tabular}{|c|c|c|c|c|c|c|}
\hline \multirow{2}{*}{ Tahun } & \multirow{2}{*}{$\begin{array}{c}\text { Jumlah } \\
\text { Karyawan }\end{array}$} & \multicolumn{2}{|c|}{$\begin{array}{c}\text { Unsur Indisipliner } \\
\text { Absensi Karyawan }\end{array}$} & \multirow{2}{*}{ Total } & \multirow{2}{*}{ Persentase(\%) } \\
\cline { 3 - 5 } & & Sakit & Izin & Alpha & & \\
\hline 2016 & 56 & 9 & 6 & 4 & 19 & $34.5 \%$ \\
\hline 2017 & 55 & 7 & 9 & 3 & 19 & $34.5 \%$ \\
\hline 2018 & 63 & 9 & 11 & 5 & 25 & $39.7 \%$ \\
\hline
\end{tabular}

Sumber: Koperasi KSPPS BMT AL-FATH IKMI

Berdasarkan data dari absensi dari tabel 1 menunjukkan jumlah karyawan tahun 2016 sebanyak 56 karyawan. Total keseluruhan absensi karyawan sebanyak 19 dengan persentase sebanyak 34,5\%. Berdasarkan jumlah karyawan tahun 2017 sebanyak 55 karyawan. Total keseluruhan absensi karyawan sebanyak 19 karyawan dengan persentase sebanyak 34.5\%. Sedangkan ditahun 2018 total keseluruhan absensi karyawan sebanyak 25 karyawan denganpersentase sebanyak $39.7 \%$. Hal ini membuktikan bahwa di Koperasi KSPPS BMT AL-FATH IKMI mengalami peningkatan di tahun 2018.

Tabel 2. Data Pencapaian Target Keuangan

Gabungan KSPPS BMT AL-FATH IKMI Kedaung Pamulang (2017)

\begin{tabular}{|c|c|c|c|c|}
\hline No & Pos-Pos & $\begin{array}{c}\text { Target Desember } \\
\text { 2017 }\end{array}$ & $\begin{array}{c}\text { Realisasi Desember } \\
\mathbf{2 0 1 7}\end{array}$ & $\begin{array}{c}\text { Capaian } \\
\mathbf{( \% )}\end{array}$ \\
\hline 1 & Pembiayaan & Rp. 66.521.815.214 & Rp. 52.170 .120 .100 & $78 \%$ \\
\hline 2 & Pendapatan & Rp. 9.007.566.740 & Rp. 8.366.783.470 & $93 \%$ \\
\hline 3 & $\begin{array}{c}\text { Tabungan } \\
\text { Dan Modal }\end{array}$ & Rp. 37.024.918.109 & Rp. 38.801 .361 .220 & $105 \%$ \\
\hline 4 & SHU Bersih & Rp. 649.013.323 & Rp. 432.446 .537 & $67 \%$ \\
\hline
\end{tabular}

Sumber: Manager Koperasi KSPPS BMT AL-FATH IKMI

Tabel 3. Data Pencapaian Target Keuangan

Gabungan KSPPS BMT AL-FATH IKMI Kedaung Pamulang (2018)

\begin{tabular}{|c|c|c|c|c|}
\hline No & Pos-Pos & $\begin{array}{c}\text { Target Desember } \\
\mathbf{2 0 1 8}\end{array}$ & $\begin{array}{c}\text { Realisasi } \\
\text { Desember 2018 }\end{array}$ & $\begin{array}{c}\text { Capaian } \\
\text { (\%) }\end{array}$ \\
\hline 1 & Pembiayaan & Rp. 79.515.015.897 & Rp. 58.946.852.051 & $74 \%$ \\
\hline 2 & Pendapatan & Rp. 10.420.666.972 & Rp. 9.316.603.722 & $89 \%$ \\
\hline 3 & $\begin{array}{c}\text { Tabungan } \\
\text { Dan Modal }\end{array}$ & Rp. 44.513.861.853 & Rp.38.205.162.856 & $86 \%$ \\
\hline 4 & SHU Bersih & Rp. 653.093.403 & Rp. 367.530.118 & $56 \%$ \\
\hline
\end{tabular}

Sumber: Manager Koperasi KSPPS BMT AL-FATH IKMI

Berdasarkan tabel 2 dan 3 dapat dilihat kinerja karyawan di Koperasi KSPPS BMT AL-FATH IKMI yang merupakan cerminan kinerja karyawan dari tahun 2017 dan 2018. Pada tahun 2017 jumlah total pendapatan mencapai $93 \%$ tetapi pada tahun 2018 jumlah total pendapatan hanya mencapai $89 \%$ menunjukkan penurunan yang kurang baik. Pada tahun 2017 jumlah total tabungan dan modal mencapai $105 \%$ tetapi pada tahun 2018 jumlah total tabungan dan modal hanya mencapai $86 \%$ 
menunjukkan penurunan yang kurang baik. Sedangkan pada tahun 2017 jumlah total SHU bersih hanya mencapai $67 \%$ tetapi pada tahun 2018 jumlah total SHU bersih menunjukkan penurunan hanya mencapai 56\%. Hal ini membuktikan bahwa pada tahun 2017 jumlah total pembiayaan, pendapatan dan tabungan modal lebih baik dibanding tahun 2018. Akan tetapi, jumlah total SHU bersih ditahun 2017 mengalami penurunan dan membuktikan peningkatannya ditahun 2018. Dari tabel tersebut dapat diketahui bahwa kinerja karyawan di Koperasi KSPPS BMT ALFATH IKMI masih belum sesuai dengan yang diharapkan.

Kinerja karyawan yang menurun akan menghambat pelaksanaan tujuan intansi karena karyawan kurang tekun menyelesaikan pekerjaannya sehingga pekerjaan menjadi tertunda dan tidak selesai pada waktu yang telah ditentukan. Hal ini akan sangat merugikan bagi intansi maupun karyawannya sendiri. Adanya lingkungan dan disiplin kerja yang baik diharapkan kinerja karyawan dapat meningkat. Kelancaran proses kerja akan mempermudah tercapainya tujuan dari perusahaan.

Berdasarkan latar belakang sesuai dengan masalah yang terjadi di Koperasi KSPPBMT AL-FATH IKMI Kedaung Pamulang yaitu menurunnya disiplin kerja dan kinerja karyawan. Diketahui beberapa faktor variabel penting yang mempengaruhi kinerja karyawan dia ntaranya lingkungan kerja dan disiplin kerja.

\section{TINJAUAN PUSTAKA}

\section{Lingkungan kerja}

Lingkungan kerja menurut pendapat Nitisemito dalam Gardjito (2014:3) adalah segala sesuatu yang ada disekitar para pekerja dan dapat mempengaruhi dirinya dalam menjalankan tugas- tugas yang dibebankan. Berdasarkan definisi tersebut dapat diketahui bahwa lingkungan kerja ialah kondisi atau situasi mempengaruhi cukup besar terhadap pegawai dalam melakukan pekerjaan atau terhadap jalannya operasi perusahaan.

\section{Disiplin Kerja}

Disiplin adalah sikap atau perilaku seseorang yang sesuai dengan peraturan organisasi tempat ia bekerja. Disiplin kerja dapat dilihat sebagai sesuatu yang besar manfaatnya, baik bagi kepentingan organisasi maupunbagi karyawan.

Menurut Singodimedjodalam Edy Sutrisno (2016:86), menyatakan bahwa Disiplin adalah "sikap kesediaan dan kerelaan seseorang untuk mematuhi dan menaati norma-norma peraturan yang berlaku disekitarnya".

\section{Kinerja Karyawan}

Kinerja merupakan tingkat pencapaian atau hasil kerja seseorang dari sasaran yang harus dicapai atau tugas yang harus dilaksanakan sesuai dengan tanggung jawab masing-masing dalam periode waktu tertentu. Menurut Rival (dalam Muhammad Sandy (2015:12)menyatakan bahwa kinerja atau prestasi kerja adalah hasil atau tingkat keberhasilan seseorang secara keseluruhan selama periode tertentu didalam melaksanakan tugas dibandingkan berbagai kemungkinan, seperti standar hasil kerja, target sasaran atau kriteria yang telah ditentukan terlebih dahulu dan telahdisepakati.

\section{METODE}

Jenis penelitian ini yaitu menggunakan metode penelitian analisis kuantitatif, yaitu menggunakan analisis data secara mendalam dalam bentuk angka. Dalam penelitian ini penulis melakukan penelitian di Koperasi KSPPS BMT ALFATH IKMI yang beralamat di Jl. Aria Putra No.7 Kedaung Pamulang. Waktu penelitian ini berlangsung pada bulan Oktober 2019 sampai Mei 2020. Populasi dalam penelitian ini yaitu seluruh karyawan yang bekerja pada di Koperasi KSPPS BMT AL-FATH IKMI sebanyak 63 karyawan. Sampel dalam penelitian ini adalah seluruh karyawan yang bekerja pada di Koperasi KSPPS BMT AL-FATH 
IKMI sebanyak 63 karyawan.

\section{HASIL DAN PEMBAHASAN}

\section{Analisis Deskriptif}

Analisis deskriptif adalah statistik yang digunakan untuk menganalisa data dengan cara mendeskripsikan atau menggambarkan data yang telah terkumpul sebagaimana adanya tanpa bermaksud membuat kesimpulan yang berlaku untuk umum atau generalisasi.

Dari hasil total responden lingkungan kerja yang menjawab sangat setuju $8,49 \%$, yang menjawab setuju $11,92 \%$, yang menjawab kurang setuju $1,63 \%$, yang menjawab tidak setuju $0,06 \%$ dan yang menjawab sangat tidak

\section{Analisis Kuantitatif}

Pada analisis ini dimaksudkan untuk mengetahui pengaruh variabel independen terhadap variabel dependen. Adapun hasil pengujian sebagai berikut:

\section{a. Analisis Regresi Linier Berganda}

Uji regresi berganda ini dimaksudkan untuk mengetahui

Tabel 4. Uji Regresi Linear Berganda

Coefficients $^{\mathrm{a}}$

\begin{tabular}{|c|c|c|c|c|c|c|}
\hline \multirow[b]{2}{*}{ Mod } & & \multicolumn{2}{|c|}{ Unstandardized Coefficients } & \multirow{2}{*}{$\begin{array}{c}\begin{array}{c}\text { Standardized } \\
\text { Coefficients }\end{array} \\
\text { Beta } \\
\end{array}$} & \multirow[b]{2}{*}{$t$} & \multirow[b]{2}{*}{ Sig. } \\
\hline & & B & Std. Error & & & \\
\hline \multirow[t]{3}{*}{1} & (Constant) & 14,570 & 4,249 & & 3,429 &, 001 \\
\hline & Lingkungan Kerja (X1) &, 302 & 127 &, 304 & 2,375 &, 001 \\
\hline & Disiplin Kerja (X2) & .533 & 162 & .423 & 3,300 & .002 \\
\hline
\end{tabular}

a. Dependent Variable: Kinerja Karyawan $(Y)$

Sumber: Hasil Pengolahan Data SPPS 25

Berdasarkan hasil perhitungan tersebut maka dapat diperoleh persamaan regresi linear berganda $Y$ $=$

Keterangan:

$14,570+0,302 X_{1}+0,533 X_{2}$

a. Konstanta sebesar 14,570 artinya jika lingkungan kerja dan disiplin kerja, bernilai nol atau tidak meningkat maka kinerja karyawan akan tetap bernilai sebesar 14,570.

b. Nilai regresi $0,302 \quad X_{1}$ artinya apabila variabel lingkungan kerja (X1) meningkat sebesar 1 satuan dengan asumsi variabel disiplin kerja (X2) tetap, maka kinerja setuju $0 \%$. Dari uraian tersebut responden lingkungan kerja memilih setuju.

Dari hasil total responden disiplin kerja yang menjawab sangat setuju $10,05 \%$, yang setuju $11,38 \%$, yang kurang setuju $1,19 \%$, yang tidak setuju $0 \%$ dan yang sangat tidak setuju 0\%. Dari uraian tersebut responden disiplin kerja memilih setuju.

Dari hasil total responden kinerja karyawan yang menjawab sangat setuju $13,02 \%$, yang setuju $13,58 \%$, yang kurang setuju $1,66 \%$, yang tidak setuju $0,02 \%$ dan yang sangat tidak setuju $0 \%$. Dari uraian tersebut responden kinerja karyawan memilih setuju.

seberapa besar pengaruh Lingkungan Kerja (X1) dan Disiplin Kerja (X2) terhadap Kinerja Karyawan (Y), berikut ini hasil olahan data regresi linear berganda dengan bantuan SPPS versi 25 yang dapat dilihat pada tabel berikut ini: 
variabel dependen baik secara parsial pengujian sebagai berikut: maupun simultan. Adapun hasil

Tabel 5. Hasil Pengujian Koefisien Korelasi Disiplin kerja Terhadap Kinerja Karyawan.

\section{Correlations $^{\mathrm{b}}$}

\begin{tabular}{|c|c|c|c|}
\hline & & $\begin{array}{c}\text { Disiplin Kerja } \\
(\mathrm{X} 1)\end{array}$ & $\begin{array}{c}\text { Kinerja } \\
\text { Karyawan }(\mathrm{Y})\end{array}$ \\
\hline \multirow[t]{2}{*}{ Disiplin Kerja $(\mathrm{X} 1)$} & Pearson Correlation & 1 & $.652^{* *}$ \\
\hline & Sig. (2-tailed) & & .000 \\
\hline \multirow{2}{*}{$\begin{array}{l}\text { Kinerja Karyawan } \\
(\mathrm{Y})\end{array}$} & Pearson Correlation & $.652^{* *}$ & 1 \\
\hline & Sig. (2-tailed) & .000 & \\
\hline
\end{tabular}

Berdasarkan hasil pengujian hubungan yang kuat terhadap kinerja diperoleh nilai korelasi sebesar 0,652 artinya disiplin kerja memiliki karyawan.

Tabel 6. Hasil Pengujian Koefisien Korelasi Motivasi Terhadap Kinerja Karyawan.

Correlations $^{b}$

\begin{tabular}{|c|c|c|c|}
\hline & & Motivasi (X2) & $\begin{array}{c}\text { Kinerja } \\
\text { Karyawan }(\mathrm{Y})\end{array}$ \\
\hline \multirow[t]{2}{*}{ Motivasi (X2) } & Pearson Correlation & 1 & $.653^{* *}$ \\
\hline & Sig. (2-tailed) & & .000 \\
\hline \multirow[t]{2}{*}{ Kinerja Karyawan $(\mathrm{Y})$} & Pearson Correlation & $.653^{* *}$ & 1 \\
\hline & Sig. (2-tailed) & .000 & \\
\hline
\end{tabular}

Berdasarkan hasil pengujian diperoleh nilai korelasi sebesar 0,653

artinya motivasi memiliki hubungan

Tabel 7. Hasil Pengujian Koefisien Korelasi Disiplin kerja dan Motivasi secara simultan Terhadap Kinerja Karyawan.

Model Summary

\begin{tabular}{|c|c|c|c|c|}
\hline Mod & $\mathrm{R}$ & R Square & $\begin{array}{l}\text { Adjusted R } \\
\text { Square }\end{array}$ & $\begin{array}{l}\text { Std. Error of the } \\
\text { Estimate }\end{array}$ \\
\hline 1 & $.735^{a}$ & .541 & .523 & 2.404 \\
\hline
\end{tabular}

a. Predictors: (Constant), Motivasi (X2), Disiplin Kerja (X1)

Berdasarkan hasil pengujian diperoleh nilai korelasi sebesar 0,735 artinya disiplin kerja dan motivasi secara simultan memiliki hubungan yang kuat terhadap kinerja karyawan.

\section{c. Analisis Koefisien Determinasi}

\section{Uji Korelasi R}

Analisis korelasi digunakan untuk mencari hubungan antara dua variabel bebas atau lebih secara bersama-sama dihubungkan dengan variabel terikatnya. Sehingga dapat diketahui besarnya sumbangan seluruh variabel bebas yang menjadi objek penelitian terhadap variabel terikatnya. Berikut hasil pengujiannya:

Tabel 8. Uji Korelasi

\begin{tabular}{|l|c|c|c|c|}
\hline \multicolumn{6}{|c|}{ Model Summary } \\
\hline Model & $\mathrm{R}$ & Square & $\begin{array}{c}\text { Adjusted } \\
\text { R Square }\end{array}$ & $\begin{array}{c}\text { Std. Error of the } \\
\text { Estimate }\end{array}$ \\
\hline 1 & $.664 \mathrm{a}$ & .441 & .422 & 2.383 \\
\hline \multicolumn{2}{|c|}{ a. Predictors: (Constant), Disiplin Kerja, Lingkungan Kerja } \\
\hline
\end{tabular}


Dari data tabel diatas dapat dilihat hasil dari uji koefisien korelasi dengan menunjukkan nilai $R$ sebesar 0,664. Hal ini menunjukkan bahwa korelasi atau hubungan antara Kinerja Karyawan (variabel dependen) dengan Lingkungan Kerja dan Disiplin Kerja (variabel independen) mempunyai tingkat hubungan yang kuat yaitu sebesar
0,664 .

2. Uji Koefisien Determinasi $\left(\mathbf{R}^{2}\right)$

Koefisien determinasi ini digunakan untuk mengetahui seberapa kemampuan variabel bebas dalam menerangkan variabel terikat. Nilai determinasi ditentukan dengan nilai RSquare. Berikut adalah hasil uji koefisien determinasi $\left(\mathrm{R}^{2}\right)$ :

Tabel 9. Uji Koefisien Determinasi

\begin{tabular}{|l|r|r|r|r|}
\hline \multicolumn{2}{|c|}{ Model Summary } \\
\hline Model & $\mathrm{R}$ & Square & Adjusted R Square & $\begin{array}{c}\text { Std. Error of } \\
\text { the Estimate }\end{array}$ \\
\hline 1 & .6 & .441 & .422 & 2.383 \\
\hline
\end{tabular}

a. Predictors: (Constant), Disiplin Kerja, Lingkungan Kerja

Sumber: Hasil Pengolahan Data SPPS 25

Dari data diatas, Uji koefisien

determinasi dapat dilihat dari nilai $\mathrm{R}$ Square. Dari hasil pengolahan data menggunakan SPPS 25 dapat dilihat bahwa nilai $\mathrm{R}$ Square menunjukkan angka sebesar 0,441 yang berarti bahwa variabel Lingkungan Kerja (X1) dan Disiplin Kerja (X2) berpengaruh sedang terhadap Kinerja Karyawan (Y) sebesar $44,1 \%$ sedangkan sisanya sebesar $55,9 \%$ dipengaruhi oleh faktor lain yang tidak diteliti dalam penelitian ini.

\section{d. Uji Hipotesis}

\section{Uji hipotesis Parsial (Uji t)}

Kriteria penerimaan dan penolakan hipotesis adalah jika $t_{\text {hitung }}$ $>t_{\text {tabel, }}$ maka Ho diterima (adanya pengaruh signifikan), dan menolak Ha. Jika $t_{\text {hitung }}<t_{\text {tabel, }}$ maka Ho ditolak (tidak ada pengaruh) dan menerima Ha. Berdasarkan dasar signifikansi, kriterianya adalah jika signifikansi $>0,05$ maka Ho ditolak, jika signifikansi < 0,05 maka Ho diterima.

Tabel 10. Uji Hipotesis Parsial

Coefficients $^{\mathrm{a}}$

\begin{tabular}{|c|c|c|c|c|c|c|}
\hline \multirow{2}{*}{\multicolumn{2}{|c|}{ Model }} & \multicolumn{2}{|c|}{ Unstandardized Coefficients } & \multirow{2}{*}{$\begin{array}{c}\begin{array}{c}\text { Standardized } \\
\text { Coefficients }\end{array} \\
\text { Beta }\end{array}$} & \multirow[b]{2}{*}{$\mathrm{t}$} & \multirow[b]{2}{*}{ Sig. } \\
\hline & & $\mathrm{B}$ & Std. Error & & & \\
\hline \multirow[t]{3}{*}{1} & (Constant) & 14,570 & 4,249 & & 3,429 & 001 \\
\hline & Lingkungan Kerja (メ1) &, 302 & 127 & ,304 & 2,375 &, 001 \\
\hline & Disiplin Kerja (X2) & 533 & 162 & 423 & 3,300 &, 002 \\
\hline
\end{tabular}

a. Dependent Variable: Kinerja Karyawan ( $($ )

Dapat disimpulkan bahwa variabel Lingkungan kerja secara parsial mempunyai pengaruh signifikan terhadap kinerja karyawan. Dari data tabel diatas, bahwa variabel Disiplin Kerja memiliki $t_{\text {hitung }}$ sebesar 3,300 lebih besar dari $t_{\text {tabel }}(2,000)$. Karena nilai $t_{\text {hitung }}$ lebih besar dari $t_{\text {tabel }}$ $(3,300>2,000)$, maka Ho ditolak dan $\mathrm{Ha}$ diterima. Hal ini diperkuat dengan nilai signifikansi Disiplin
Kerja yang lebih kecil dari 0,05 (0,002< $0,05)$. Sehingga dapat disimpulkan bahwa variabel Disiplin Kerja secara parsial mempunyai pengaruh signifikan terhadap kinerja karyawan.

\section{Uji Hipotesis Simultan (Uji F)}

Uji $F$ dikenal dengan uji serentak atau Uji Model/ Uji Anova, yaitu uji untuk melihat bagaimanakah pengaruh semua variabel bebasnya 


\begin{tabular}{lccc} 
secara & bersama-sama & terhadap & \multicolumn{2}{l}{ lingkungan kerja dan disiplin kerja } \\
variabel & terikatnya. & Pengujian & secara bersama-sama berpengaruh \\
hipotesis & secara & simultan & secara signifikan terhadap kinerja \\
menunjukkan & bahwa & variabel & karyawan. \\
& & Tabel 11. Uji Hipotesis Simultan
\end{tabular}

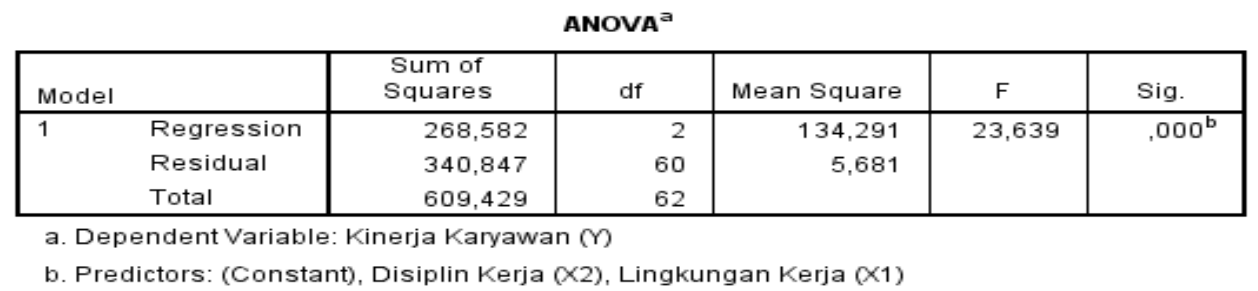

Dari data tabel diatas, bahwa hasil uji statistik $F$ memiliki nilai probabilitas sebesar sig 0,000<0,05. Dengan demikian Ha diterima dan menolak Ho. Hal tersebut dapat diperkuat dengan nilai $f_{\text {hitung }}$ sebesar 23,639 dengan $f_{\text {tabel }} 3,15$ sehingga nilai $\mathrm{f}_{\text {hitung }}=23,639>\mathrm{f}_{\text {tabel }}=3,15$ Dari hasil tersebut dapat disimpulkan bahwa kedua variabel independen dan dependen secara bersama-sama berpengaruh yaitu Lingkungan Kerja dan Disiplin Kerja berpengaruh signifikan dan simultan terhadap Kinerja Karyawan.

\section{PEMBAHASAN HASIL PENELITIAN}

1. Pengaruh Lingkungan Kerja dengan Kinerja Karyawan (Y)

Dari hasil penelitian yang sudah dilakukan didapatkan bahwa Lingkungan Kerja berpengaruh positif terhadap Kinerja Karyawan. Berdasarkan analisis regresi linear berganda yang diperoleh antara Lingkungan Kerja (X1) terhadap Kinerja Karyawan (Y) adalah sebesar 0,302 dalam nilai telah dinyatakan positif yang menunjukkan bahwa hubungan yang terjadi antara variabel bebas dengan variabel terikat adalah searah. Sehingga dalam pengamatan terhadap Lingkungan Kerja di Koperasi KSPPS BMT AL-FATH IKMI Kedaung Pamulang harus lebih dilengkapi fasilitas untuk kepentingan karyawan sehingga tidak mengganggu aktivitas karyawan untuk melakukan pekerjaan.
2. Pengaruh Disiplin Kerja (X2) dengan Kinerja Karyawan (Y)

Dari hasil penelitian yang sudah dilakukan didapatkan bahwa Disiplin Kerja berpengaruh positif terhadap Kinerja Karyawan. Berdasarkan analisis regresi linear berganda yang diperoleh antara Disiplin Kerja (X1) terhadap Kinerja Karyawan (Y) adalah sebesar 0,533 dalam nilai telah dinyatakan positif yang menunjukkan bahwa hubungan yang terjadi antara variabel bebas dengan variabel terikat searah. Sehingga dalam pengamatan terhadap Disiplin Kerja di Koperasi KSPPS BMT AL-FATH IKMI Kedaung Pamulang harus lebih baik lagi agar karyawan dapat disiplin dengan baik.

3. Pengaruh Lingkungan Kerja (X1) dan Disiplin Kerja (X2) terhadap Kinerja Karyawan (Y)

Berdasarkan hasil uji statistik $F$ memiliki probabilitas sebesar sig 0,000 $<0,05$ atau dengan nilai $F_{\text {hitung }}$ sebesar 23,639 dengan $F_{\text {tabel }} 3,15$ sehingga nilai $F_{\text {hitung }}=23,639>$ dari $F_{\text {tabel }}=3,15$. Dengan demikian, Ha diterima dan Ho ditolak.Dari hasil tersebut dapat disimpulkan bahwa kedua variabel Lingkungan Kerja dan Disiplin Kerja secara bersama-sama berpengaruh positif dan signifikan terhadap Kinerja Karyawan di Koperasi KSPPS BMT ALFATH IKMI Kedaung Pamulang. Dengan adanya Lingkungan Kerja dan Disiplin Kerja, maka dapat meningkatkan Kinerja Karyawan. 


\section{PENUTUP}

\section{Kesimpulan}

1. Lingkungan kerja di koperasi KSPPS BMT AL-FATH IKMI Kedaung Pamulang sudah cukup baik, yakni dinyatakan dari hasil kuesioner responden sebanyak 63 karyawan dengan 8 pernyataan, yakni karyawan yang sangat setuju sebanyak $8,49 \%$, karyawan yang setuju sebanyak $11,92 \%$, karyawan yang kurang setuju sebanyak $1,63 \%$, karyawan yang tidak setuju sebanyak $0,06 \%$ dan karyawan yang sangat tidak setuju sebanyak $0 \%$.

2. Disiplin kerja di koperasi KSPPS BMT AL-FATH IKMI Kedaung Pamulang sudah cukup baik, yakni dinyatakan dari hasil kuesioner responden sebanyak 63 karyawan dengan 8 pernyataan, yakni karyawan yang sangat setuju sebanyak $10,05 \%$, karyawan yang setuju sebanyak $11,38 \%$, karyawan yang kurang setuju sebanyak 1,19\%, karyawan yang tidak setuju sebanyak $0 \%$ dan karyawan yang sangat tidak setuju sebanyak $0 \%$.

3. Kinerja karyawan di koperasi KSPPS BMT AL-FATH IKMI Kedaung Pamulang sudah cukup baik, yakni dinyatakan dari hasil kuesioner responden sebanyak 63 karyawan dengan 10 pernyataan, yakni karyawan yang sangat setuju sebanyak 13,02\%, karyawan yang setuju sebanyak $13,58 \%$, karyawan yang kurang setuju sebanyak $1,66 \%$, karyawan yang tidak setuju sebanyak 0,02\% dan karyawan yang sangat tidak setuju sebanyak $0 \%$.

\section{Saran}

Koperasi KSPPS BMT AL- FATH IKMI Kedaung Pamulang hendaknya memberikan pembinaan dalam rangka menjaga kebersihan lingkungan kerja dan menciptakan lingkungan kerja yang mendukung kinerja karyawan dan hendaknya memberikan pembinaan dalam rangka meningkatkan disiplin kerja agar kinerja karyawan lebih baik.

Penelitian lebih lanjut untuk mengkaji pengaruh lingkungan kerja dan disiplin kerja terhadap kinerja karyawan sebaiknya diperluas lagi disamping itu jumlah sampel penelitian sebaiknya ditambah, termasuk lokasi penelitian diperluas sehingga diharapkan dapat diperoleh hasil yang lebih untuk dijadikan dasar penelitian.

\section{DAFTAR PUSTAKA}

Affandi, A., et al. (2020). Optimization of MSMEs Empowerment in Facing Competition in the Global Market during the COVID-19 Pandemic Time. Systematic Reviews in Pharmacy, 11(11), 1506-1515.

Affandi, A., et al.. (2020). Optimization of MSMEs Empowerment in Facing Competition in the Global Market during the COVID-19 Pandemic Time. Systematic Reviews in Pharmacy, 11(11), 1506-1515.

Alex S. Nitisemito. 2002. Wawasan Sumber Daya Manusia, Penerbit: Pustaka Utama Grafiti.

Edy Sutrisno, 2016. Manajemen Sumber Daya Manusia. Jakarta: Prenadamedia Group.

Ekhsan, M. (2019). Pengaruh Motivasi dan Disiplin Kerja terhadap Kinerja Karyawan. Optimal: Jurnal Ekonomi dan Kewirausahaan, 13(1), 1-13.

Gusti, P. N. F., et al.. (2021). Pengaruh Human Relation Dan Motivasi Kerja Terhadap Kinerja Karyawan Pada PT. Bank Rakyat Indonesia (Persero) TBK Cabang Sorong. Jurnal Ekonomi Efektif, 3(4), 456-463.

Hariandja, M. 2002. Manajemen Sumber Daya Manusia. Jakarta: Bumi Aksara.

Hasibuan, Malayu S. P. 2003. Manajemen Sumber Daya Manusia, Bumi Aksara,Jakarta.

Kasmir, 2016. Manajemen Sumber Daya Manusia (teori dan praktik). Jakarta: PT. Raja Grafindo Persada.

Mangkunegara. Anwar Prabu. 2003. Manajemen Sumber Daya Manusia Perusahaan. PT. Remaja Rosdakarya. Bandung. 2004. Perencanaan dan Pengembangan Sumber Daya Manusia. Bandung: PT. Refika Aditama. 
Muslimat, A., et al.. (2020). Effect Of Organizational Commitment On The Sustainability Performance Of Indonesian Industries. PalArch's Journal of Archaeology of Egypt/Egyptology, 17(6), 8330-8347.

Nurjaya, N., et al. (2021). Pengaruh Kompetensi Sumber Daya Manusia Dan Kemampuan Pemanfaatan Teknologi Terhadap Kinerja Aparatur Desa Pada Kantor Kepala Desa Di Kabupaten Gunungkidul, Yogyakarta. JENIUS (Jurnal Ilmiah Manajemen Sumber Daya Manusia), 4(3), 332-346.

Nurjaya, N., et al.. (2020). Edupreneurship management in shaping the nation's character. Jurnal Konseling dan Pendidikan, 8(3), 198-206.

Nurjaya, N., et al.. (2020). The Effect of Work Stress and Work Conflict on Employees Turnover Intention In Middle Small Micro Enterprises (MSMEs) In South Tangerang Region. International Journal of Educational Administration, Management, and Leadership, 51-62.

Prawirosentono, Suyadi. 2002. Kebijakan Kinerja Karyawan. Yogyakarta: BPFE.

Rivai, Veithzal. 2005. Manajemen Sumber Daya Manusia Untuk Perusahaan Dari Teori ke Praktek. PT. Raja Grafindo Persada. Jakarta.

Saydam, G.2000. Manajemen Sumber Daya Manusia (human resources management). Jakarta: Djambatan.

Sedarmayanti, 2009. Manajemen Sumber Daya Manusia, Reformasi Birokrasi
Manajemen Pegawai Negeri Sipil. Rafika Aditama, Bandung, 2014. Sumber Daya Manusia dan Produktivitas Kerja. Jakarta: Mandar Maju.

Siagian, Sondang. P. 2014. Manajemen Sumber Daya Manusia. Jakarta: Bumi Aksara.

Sihombing, S. 2004. Manajemen Sumber Daya Manusia. Jakarta: Balai Pustaka.

Simamora, Henry. 1996. Manajemen Sumberdaya manusia, STIE YKPN, Yogyakarta.

Sinambela, Lijan Poltak. 2016. Manajemen Sumber Daya Manusia. Jakarta: PT. Bumi Aksara.

Singarimbun, M dan Sofian Efendi. 2006. Metode Penelitian Survei. Jakarta: LP3ES.

Sugiyono, Metode Penelitian Kuantitatif Kualitatif dan RED CV, Bandung: Alfabeta, 2016.

Sulastri, L., et al.. (2020). The Role of Decision Support System and Risk Management Using Social Media Promotion. International Journal of Psychosocial Rehabilitation, 24(1).

Sunarsi, D. (2017). Pengaruh Kepemimpinan Dan Budaya Organisasi terhadap Kinerja Karyawan Pada Cabang Pembantu Bank DKI Pondok Labu-Jakarta Selatan. JENIUS, 1(2), 21.

Suyadi Prawirosentono. 1999. Manajemen S.D.M. Kebijakan Kinerja Karyawan, BPFE, Yogyakarta.

T Hani Handoko.1999. Manajemen Personalia dan Sumberdaya Manusia. BPFE, Yogyakarta. 